\title{
Avaliação de Funcionamento da UPA 24 H de Capim Grosso
}

\author{
Fernanda Santos Lima ${ }^{1}$; Gilson da Silva Santos ${ }^{2}$; Grasiela de Oliveira Silva ${ }^{3}$; \\ Manoel Junior Ferreira do Nascimento ${ }^{4}$; Lucimara Araújo Campos Alexandre ${ }^{5}$
}

Resumo: Trata-se de um estudo de caso que buscou descrever o funcionamento da Unidade de Pronto Atendimento. A coleta de dados ocorreu através de entrevistas e análise de relatórios, tendo como sujeitos do estudo profissionais que tratam diretamente com gestão financeira e administrativa da unidade estudada. Os resultados indicam que a instituição é referência na assistência às urgências tanto para o município sede como para os municípios circunvizinhos. Os resultados apontam a necessidade da Atenção Básica de se integrar com os demais níveis de atenção para o sucesso da proposta da PNAU.

Palavras chaves: Unidade de Pronto Atendimento, Atenção Básica, PNAU

\section{UPA 24H Evaluation of Operation in Capim Grosso}

\begin{abstract}
This is a case study that sought to describe the functioning of the Er unit. Data collection occurred through interviews and analysis of reports, having as subject the study professionals dealing directly with financial and administrative management of the studied unit. The results indicate that the institution is in reference to emergency assistance for both the county seat and the surrounding municipalities. The results highlight the need of basic attention to integrate with the other levels of attention to the success of the proposal of PNAU.
\end{abstract}

Keywords: Er unit, basic attention, PNAU.

\section{Introdução}

O Sistema Único de Saúde (SUS) tem como princípio a organização dos serviços de forma hierarquizada e regionalizada. Neste sentido, a rede de saúde deve ser composta por diversos pontos de atendimento, articulados e resolutivos, que atendam situações crônicas e agudas da população, constituídos por Unidades Básicas de Saúde (UBS), e todos os serviços de suporte, ambulatórios de especialidades, Unidades de Pronto Atendimento (UPA) e hospitais.

\footnotetext{
${ }^{1}$ Fernanda Santos Lima graduanda pela Universidade Federal do Vale do São Francisco - Univasf.

${ }^{2}$ Gilson da Silva Santos graduando pela Universidade Federal do Vale do São Francisco - Univasf.

${ }^{3}$ Grasiela de Oliveira Silva graduanda pela Universidade Federal do Vale do São Francisco - Univasf. grazyoliveira583@gmail.com

${ }^{4}$ Manoel Junior Ferreira do Nascimento Santos graduando pela Universidade Federal do Vale do São Francisco - Univasf.

${ }^{5}$ Lucimara Araújo Campos Alexandre Profa. M. Sc., Professora Assistente do Colegiado de Enfermagem Universidade Federal do Vale do São Francisco. Contato: lucimara.univasf@gmail.com.
} 
No contexto do atendimento de eventos agudos, os serviços são estruturados para compor a Rede de Atenção às Urgências (UPA, SAMU), que devem ser auxiliares, atuantes e integrantes ao componente pré-hospitalar, segundo preconização da Política Nacional de Atenção às Urgências (ORITA, SOUZA, OLIVEIRA, 2010).

Nesse sentido, as UPA's são componentes de uma Rede Organizada de Atenção às Urgências, de complexidade intermediária, situado entre a Atenção Primária e a Rede Hospitalar, tendo como principal objetivo desafogar os prontos-socorros hospitalares e agilizar o atendimento de urgências (BRASIL, 2017). Essas unidades trabalham de forma articulada com a atenção primária à saúde, SAMU 192 e hospitais, sendo necessário, para sua habilitação e qualificação, dentre outros requisitos, que o mesmo seja coberto por unidade de SAMU 192, uma vez que o mesmo se constitui como uma das portas de entrada na UPA, através de chamadas telefônicas e atendimento com ambulância de acordo com a gravidade. (BRASIL 2017) e Konder e O’Dwyer, (2015).

Essas unidades surgem como uma das estratégias da Política Nacional de Atenção às Urgências para a melhor organização da assistência, articulação dos serviços; e definição de fluxos e referências resolutivas (BRASIL 2006). Com implantação e custeio mensal de responsabilidade tripartite condicionada à habilitação e qualificação das unidades, cabendo a União um valor fixo mensal e a complementação compartilhado entre estado e município (BRASIL 2017). As UBS, por sua vez, tem como missão principal o alcance de um grau de resolubilidade de ações que possa evitar o agravamento das situações mórbidas referenciadas, com vistas a reduzir ao máximo a evolução de agravos que possam demandar uma atenção de maior complexidade (Silva 2011)

Desta forma, torna-se primordial a integração e articulação entre os diferentes níveis de atenção para assegurar a otimização dos recursos e o atendimento integral e resolutivo às necessidades dos usuários.

Diante do exposto, o estudo objetivou-se a avaliar uma Unidade de Pronto Atendimento com foco no panorama de atividade, recursos humanos, manutenção de material, financeira e relevância para a Região coberta. 


\section{Metodologia}

Levando em consideração o objeto de estudo, optou-se por fazer um estudo de caso com abordagem qualitativa, observacional, descritiva. O método qualitativo preocupa-se em analisar e interpretar aspectos mais profundos, descrevendo a complexidade do comportamento humano. Fornece análise mais detalhada sobre as investigações, hábitos, atitudes e tendências de comportamentos. (Marconi e Lakatos, 2011).

A pesquisa descritiva visa à identificação, registro e análise das características, fatores ou variáveis que se relacionam com o fenômeno ou processo. Esse tipo de pesquisa pode ser identificada com uma estudo de caso onde, após a coleta de dados, e realizada uma análise das relações entre as variáveis para posterior determinação de efeitos resultantes em uma empresa, sistema de produção ou produtos (Perovano 2014).

O estudo foi realizado na UPA $24 \mathrm{~h}$ de Capim Grosso, localizada no bairro Novo Oeste, que atende à demanda livre e espontânea de urgência e emergência da população da cidade sede, cidades circunvizinhas e pessoas de passagem. A cidade de Capim Grosso possui população estimada em 2016 de 31.181 habitantes e encontra-se em excelente localização geográfica fazendo limites com os municípios de São José do Jacuípe, Quixabeira, Jacobina, Caem, Queimadas e Santa Luz. (IBGE 2010)

A definição dos portes varia de acordo com a realidade loco regional, levando-se em conta a sazonalidade apresentada por alguns tipos de afecções, como, por exemplo, o aumento de demanda por doenças e agravos (BRASIL 2017)

Os sujeitos entrevistados foram a Secretária de Saúde do Município responsável pela unidade e o Coordenador da UPA. O critério utilizado para a escolha dos profissionais entrevistados, foi trabalhar diretamente nas atividades de gestão financeiro e administrativa da unidade de saúde estudada.

A coleta de dados ocorreu através de entrevista e análise de relatórios do período de abril a junho de 2017. Para a entrevista, utilizou-se um questionário de pesquisa contendo perguntas subjetivas relativas à pesquisa, de forma clara e estruturada, as quais abordavam questões acerca do funcionamento da instituição, com a possibilidade de inclusão de perguntas complementares, conforme a necessidade de entendimento mais preciso. As 
entrevistas foram realizadas no ambiente de trabalho dos sujeitos da pesquisa, em sala reservada, de modo que não interferiu na rotina da unidade.

\section{Discussão e Resultados}

A partir dos dados obtidos através das entrevistas e documentos coletados, foi possível estabelecer algumas considerações sobre a unidade estudada.

A UPA de Capim Grosso é o único estabelecimento para fluxos de referência e contra referência do município e seu loco regional, uma vez que é o único estabelecimento de saúde de complexidade intermediária de uma região de vasto território.

Assim, partindo-se das informações coletadas, foram organizadas categorias e subcategorias de análises que serão apresentadas e tratadas a seguir.

Desta forma, o estudo expõe três categorias que se compõe da seguinte forma: categoria 1- Panorama das Atividades, categoria 2 - Manutenção da Unidade, categoria 3 Relevância da Unidade para Região.

\section{Panorama das Atividades}

De acordo com as entrevistas e análise dos relatórios disponibilizados, notou-se que as atividades desenvolvidas na unidade segue as diretrizes redefinidas pela Portaria 10/2017. A instituição funciona de modo ininterrupto, 24 (vinte e quatro) horas por dia, em todos os dias da semana, incluindo feriados e pontos facultativos. Conta com equipe médica (médicos, enfermeiros, técnicos de enfermagem e auxiliares de enfermagem), equipe de limpeza/ higiene, recepção e segurança em regime de plantão e profissionais que trabalham em horário administrativo/sobreaviso como: coordenação, jardinagem, radiologia, farmácia e serviço social. A unidade funciona como base de apoio do SAMU 192, que é requisito importante para implantação do componente UPA, conforme a Política Nacional de Atenção às Urgências. 
Quanto aos atendimentos, a UPA segue ao protocolo de acolhimento e classificação de risco, cujo objetivo é identificar os pacientes que necessitam de atendimento prioritário, de acordo com a gravidade clínica, potencial de risco, agravos à saúde ou grau de sofrimento (BRASIL 2017).

Como uma das problemáticas apresentadas, constatamos alto número de atendimentos (Ambulatorial e Urgência relativa) que podem ser realizados nas Unidades Básicas de Saúde, no entanto os pacientes acabam recorrendo a UPA não só nos fins de semana e feriados, mas durante a semana, pois não encontram ou não buscam o serviço na atenção básica, dessa forma constatou-se que os serviços propriamente destinada a UPA (Urgência relativa e Emergência) equivalem a apenas $25 \%$ (vinte e cinco por cento) de todo atendimento realizado pela instituição no período analisado.

\section{Manutenção da Unidade}

O estabelecimento é de gestão municipal com atividade ambulatorial, urgência e emergência para os níveis de atenção básica e média complexidade atendimento por demanda espontânea e referenciado. A Unidade conta com 2 consultórios médicos, sala de acolhimentos com classificação de risco, sala de estabilização, sala de repouso feminino masculino e pediátrica, serviço especializados de diagnósticos por imagem, urgência e emergência. Dispõe de equipe multidisciplinar composto por médicos clínicos, enfermeiros, técnicos e auxiliares de enfermagem, farmacêutico, tecnólogo e técnico em radiologia, assistente social. Também conta com equipe de apoio como recepcionista, higiene/limpeza, almoxarifado e coordenação própria.

A UPA de Capim Grosso se enquadra como uma unidade III, como definido na postaria ministerial 10/2017. Segundo os sujeitos A e B, as despesas mensais da UPA 24h de Capim Grosso giram em torno de $\mathrm{R} \$ 350.000,00$ (trezentos e cinquenta mil reais) mensais e seu custeio conta com repasse do governo Federal de $\mathrm{R} \$ 100.000,00$ (cem mil reais) mensais por ser habilitada e R \$70.000,00 (setenta mil reais) por ser qualificada, cabendo ao município arcar com as demais despesas uma vez que não recebe a contra partida do Estado como redefinido na portaria 10/2017 onerando assim o financeiro da saúde do município. 
Os entrevistados relataram a tentativa de acordo de pactuação entre os municípios atendidos pela UPA Capim Grosso com o intuito de obter ajuda no fornecimento de material, visto que seus munícipes são atendidos nesta unidade. Porém não obtiveram retorno significativos. Apenas três dos municípios atendidos cederam um profissional técnico de enfermagem como ajuda.

\section{Relevância da Unidade para a região}

A UPA de Capim Grosso é o único estabelecimento para fluxos de referência e contra referência do município e de municípios circunvizinhos, uma vez que é o único estabelecimento de saúde de complexidade intermediária de uma região de vasto território.

Ao longo da análise dos relatórios de atendimentos dos meses de março, abril e maio de 2017, constatou-se um variado número de cidades, totalizando nesse três meses 56 cidades diferentes. Isso se deve a localização geográfica do município que se encontra em um excelente eixo rodoviário. Não obstante, a percentagem maior dos atendimentos é de moradores do município de Capim Grosso.

\section{Conclusão}

Os resultados revelaram que a unidade estudada configura-se como uma unidade de saúde de referência para o município de Capim Grosso e municípios circunvizinhos, mostrando se como local de atendimento rápido e resolutivo nos casos de urgências, mas destaca a modo equivocado que a Unidade vem sendo usada para casos ambulatoriais.

Com isso, foi possível definir alguns obstáculos na articulação da rede, presente principalmente na Atenção Primária. Entre eles é possível apontar a necessidade da Atenção Básica integrar-se com os demais níveis de atenção para o sucesso da proposta da PNAU.

É importante ressaltar a importância de realização de novos estudos nesse nível de atenção, tendo em vista a carência de artigos periódicos voltados a assistência ás urgências. 
Id on Line Revista Multidisciplinar e de Psicoloqia

Id on Line Multidisciplinary and Psycology Journal

\section{Referências}

Orita, PTK; Souza, JC; Oliveira, RG - Upa na Rede de Atenção à Saúde na Região Noroeste do Paraná: Um Estudo Descritivo- Disponível em:

www.cesumar.br/prppge/pesquisa/mostras/quin_mostra/patricia_tiemi_kikuti_orita_1.pdfAnai s Eletrônico V Mostra a I Interna de Trabalhos de Iniciação Científica CESUMAR Centro Universitário de Maringá Maringá - Paraná) - 2010

IBGE, CIDADES- Capim Grosso, histórico, Disponível em:

https://cidades.ibge.gov.br/v4/brasil/ba/capim-grosso/historico acessado em: 15.06.17

PEROVANO, D.G. Manual de metodologia científica para a segurança pública e defesa social. Curitiba: Juruá, 2014.

KONDER, MARIANA TEIXEIRA; O'DWYER, GISELE. - As Unidades de ProntoAtendimento na Política Nacional de Atenção às Urgências, Physis Revista de Saúde Coletiva, Rio de Janeiro, 25 [2]: 525-545, 2015 Disponível em: http://www.scielo.br/pdf/physis/v25n2/0103-7331-physis-25-02-00525.pdf. Acessado em $\underline{13.02 .2016}$

BRASIL. Ministério da Saúde. Política nacional de atenção às urgências / Ministério da Saúde. - 3. ed. ampl. - Brasília: Editora do Ministério da Saúde, 2006. 256 p.: il. - (Série E. Legislação de Saúde)

Portaria 10,03 de Janeiro de 2017 - Redefine as diretrizes de modelo assistencial e financiamento de UPA 24 h de Pronto Atendimento como Componente da Rede de Atenção às Urgências, no âmbito do Sistema Único de Saúde. Disponível em http://www.brasilsus.com.br/index.php/legislacoes/gabinete-do-ministro/12180-portaria-n-10de-3-de-janeiro-de-2017 acessado em 24.07.2017

Silva SF. Organização de redes regionalizadas e integradas de atenção à saúde: desafios do Sistema Único de Saúde (Brasil). Ciênc Saúde Coletiva. 2011;16:2753-62.

MARCONI, M. de A. LAKATOS, E. M. Metodologia Científica. 5a ed. São Paulo: Atlas, 2011.

Como citar este artigo (Formato ABNT):

LIMA, Fernanda S.; SANTOS, Gilson da S.; SILVA, Grasiela de O.; NASCIMENTO, Manoel Júnior F.; ALEXANDRE, Lucimara A.C. Avaliação de Funcionamento da UPA 24H de Capim Grosso. Id on Line Revista Multidisciplinar e de Psicologia, 2017, vol.11, n.37, p.103-109. ISSN: 1981-1179. 